\title{
Planning of Buildings in Tropical Environment - How Disaster changed buildings?
}

\author{
Erkan Erdik ${ }^{1}$ \\ Bachelor Degree of Architecture Study Program \\ Fachhochschule Dortmund \\ Germany \\ erdik.erkan@googlemail.com
}

\begin{abstract}
As my personal heritage is from turkey and earthquakes been always something usual for me, I wanted to know how the buildings can stand such a disaster. In the following paper I would like to investigate the architecture in different parts of the world and understand how this changed the architecture by time. Also, I want to know how these influence the vernacular architecture in different countries. In the period, there has been a load of different disasters. The problem of these disasters is also mostly located in the tropics. As the climatic conditions influence the material and quality of buildings. The problems can differ in size and could occur in a big space. To pursuit the complicate topic there will be an explanation about Earthquake, furthermore there will be several examples of such a disaster. At the end we will summarize the consequences of an earthquake with a follow up of how to design for them.
\end{abstract}

Index Terms - Earthquake, EOLBREAK, Urban, Seismic

\section{INTRODUCTION}

The following paper will deal with the problematic of seismic structures in developing countries. Furthermore, it will show the essential problems which influenced the architecture during the time. To show this I will start shortly to explain the disaster earthquake and I will investigate the problems with them. At the end of this essay you will find a summarized article about a survivor of a disaster caused by earthquake.

\section{RESULT AND ANALISYS}

\section{A. Eartquake}

"To understand the disaster earthquake better we have to discuss it right from the beginning of the history. The ancient Greek philosopher Parmenides believed that the world does not move. As things like atoms and other science was not really invented at the time. He thought just the four elements fire, earth, water and earth is the only thing existing and everything beyond disappears in a void. Obviously 500 BC when Parmenides lived, the existence of atoms had not be logically inferred. So on todays thoughts we realize that everything existing around us is made from atoms and Leucippus and his student Democritus reasoned it years after Parmenides. Because not only the earth spins at its axis as it travels around the sun, but the earth crust constantly moves in a process called plate tectonics. Rocks with different temperatures and strengths move over, under and also pass one another, slowly. It is remaking the earth's surface. So where this process is most active the fault lines occur. When these plates move a tremendous energy is released and we can feel it in form of an earthquake. 
Earthquakes have been destroying buildings and cities for years. The earliest in Europe detected earthquake dates back to $580 \mathrm{BC}$. But at the early stage of history no one could understand what caused erthquakes. But as time passes and erthquakes takes a lot of building and lives the newspaper start to write about it and people record and analyze these. So it is not a surprise, that erthquakes start to form our buildings and the cities." [1].

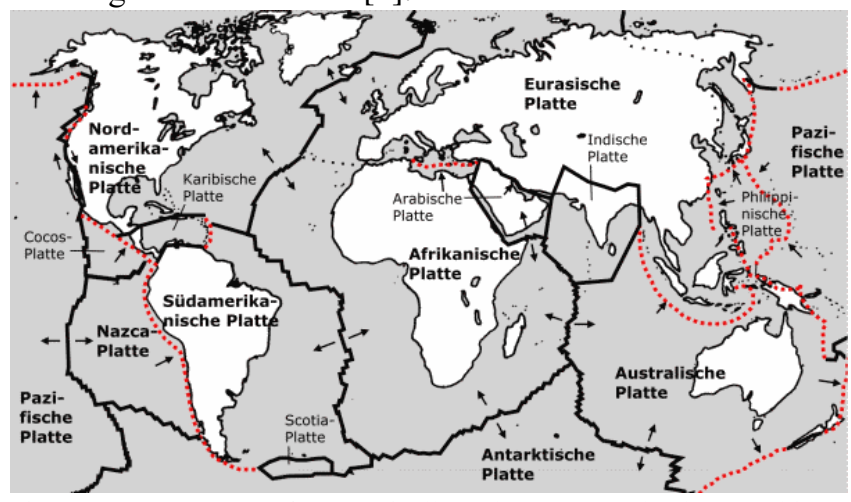

Fig. 1 Movement of tectonically plates around the world. (https://www.google.com/search?q=tektonische+platten\&safe=strict\&sxsrf $=$ ACYBGNTJ46Dt6CuTrHjEm77c-

jWang31Lg: $1575867527303 \&$ source $=1$ nms \&tbm $=i s c h \& s a=X \& v e d=2 a h U$ KEwjb9rWB5KfmAhUVfd4KHfj5BYUQ_AUoAXoECBMQAw\#imgrc= Vo6glvIusEq1fM: // 20.11.19)

\section{B. Urban Revolution}

"The Urban Revolution is the process leading to the transformation, as a result of increasing population, of villages or small towns into large, socially complex, civilized cities. Society's total urbanization is an unavoidable process. Within recent centuries, both in numbers and in global distribution, the world population has exploded and is continuing to explode. The world's population doubled from 300 million to over 600 million between $100 \mathrm{BC}$ and around $1600 \mathrm{AD}$. Improvements in medicine, living conditions and dramatic reductions in mortality rates in the next 200 years have resulted in a second doubling of 1200 million worldwide. The world population doubled by about 2,500 million between 1800 and 1950. For the third time. In less than 40 years, the fourth doubling was reached taking over 5000 million of the world's people in 1990. In 2000, 6100 million people worldwide were hit. While the population rate seems to be declining at present, it is estimated that the population will double in the next 50 years (Bilham, 1995, 2000).

However, the biggest observation of the last decades is the global urban development. When only 2 percent of the population of the country was urbanised in 1800, the number rose to $30 \%$ in 1950 , while that was at $47 \%$ in 2000. In 2008, over half of the population is projected to live in urban areas and over $60 \%$ will live in these areas by 2030 (UN-Habitat, 2005). The growth in urban areas in developing countries will rise from 0.5 billion in 1960 to 4.1 billion in 2020 , and in the developed countries, from 0.550 billion in 1960 to 1.2 billion in 2020 (Fig. 1.1). The development is not even in the world: it will be less than in developed countries.

If only one city with a population of more than 10 million (New York City) existed across 1950, there are 24 Mega Cities in 2005. Four of the cities have a population of above 20 million (Brinkhoff, 2005). Across Europe, Latin America and Africa, the most rapid urbanization happens. In 2030, the number of these continents would increase over any other large area in the world. Urban populations have only slightly increased in the developed countries, with few exceptions. Table 1.1 shows that the majority of population growth has taken place in seismic city areas. So only the latter is found in a non-seismic environment in the five super-mega cities, Osaka, Mexico City, Seoul, New York and São Paolo and 79 percent of the mega cities are clustered in seismic areas." [2].

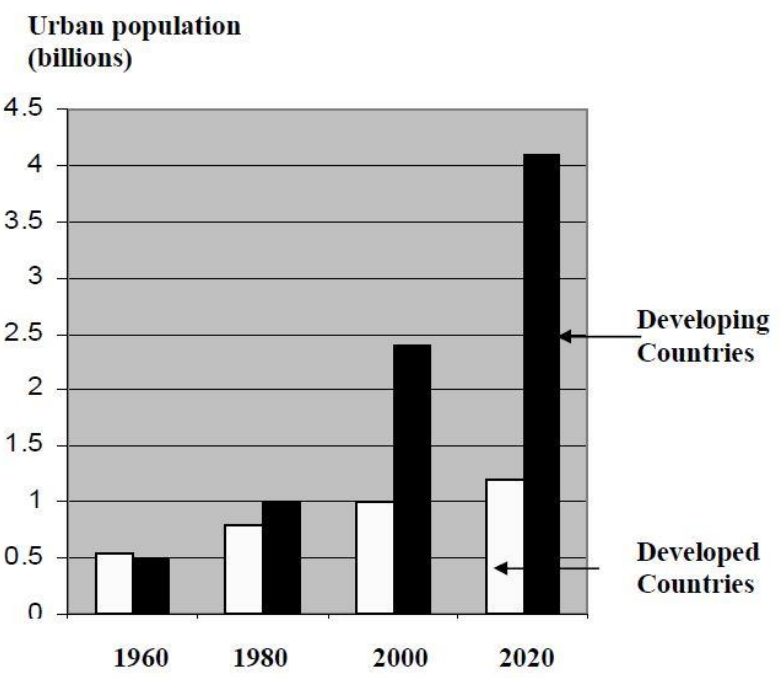

Fig. 2 Global urbanization: Increase of world's population in developed and developing countries (modified after Bilham, 2000) (Gioncu,Victor, and Federico,Mazzolani. , CRC Press LLC, 2010 - Earthquake Engineering for Structural Design ProQuest Ebook Central [p.5])

\begin{tabular}{lcccc}
\hline $\begin{array}{l}\text { Definition } \\
\text { Cities }\end{array}$ & $\begin{array}{c}\text { Population } \\
\text { million }\end{array}$ & $\begin{array}{c}\text { Total } \\
\text { number }\end{array}$ & $\begin{array}{c}\text { Situated in } \\
\text { seismic areas }\end{array}$ & $\begin{array}{c}\text { Percentage } \\
\%\end{array}$ \\
\hline Super mega & $>20$ & 5 & 4 & 80 \\
Mega & $>10$ & 19 & 15 & 79 \\
Super & $>5$ & 35 & 19 & 54 \\
Big & $>2$ & 128 & 78 & 61 \\
Important & $>1$ & 241 & 150 & 62 \\
Total & & 428 & 266 & 62
\end{tabular}

Fig. 2 (Gioncu,Victor, and Federico,Mazzolani. , CRC Press LLC, 2010 Earthquake Engineering for Structural Design ProQuest Ebook Central [p.5])

\section{Seismic Zones}

"The photo. 1.2 shows the regional seismic spread and the location of the major cities. You can see, unexpectedly, that many of these cities lie in seismically prone areas, with first place being Europe, Africa and Latin America. The vast majority of these seismic fields are in developing countries, where there is a very low level of mitigation of earthquakes.

Except for tsunamis and earthquakes, the destruction of 
people's homes and fires after hurricanes is responsible for most of the deaths associated with earthquakes. In Shansi, China, the worst earthquake in history occurred in 1556, the magnitude of which was about M 8.0. In a densely populated area, this earthquake killed 830,000 men, most of whom died in cellars sunk in poorly organized loess (wind energy slug and clay). In isolated areas far from the human population, earthquakes are mostly responsible for the killing of people. Major earthquakes in uninhabited and marginally populated areas are therefore not dangerous.

Nevertheless, an earthquake does not have to be very high if it causes severe damage in a heavily populated area. For example, five damages were: $\$ 100$ billion in earthquakes for Kobe; $\$ 40$ trillion in earthquake M 6.7; \$14 trillion in earthquakes for Chi-chi; M 7.6; $\$ 14$ trillion in earthquakes for Armenia; M 6.7 billion; and Izmit earthquake $\$ 12$ trillion, M 7.6 billion. Remember that three of these five earthquakes are not recognized as major earthquakes, since they are less than M 7.0 (Spanish version, 2002). In the next 50 years, it is anticipated, as shown, that the world population will double and that the number of important cities will increase. 62 percent of the world's major towns are now seismically susceptible, and in the future that figure needs to rise. A quick calculation shows that in the next few decades, 1 billion new housing is expected.

These are the houses that pose a future threat to urban residents and infrastructure technology in the next decade. Comprehensive reinsurance studies, specialized in earthquake activities, show that the total costs of natural disasters in the world will be 300 billion dollars a year by 2050 , with earthquakes generating the majority. It is now time to prepare city dwellers for future terrible effects. For the next era, there is a new major problem: disaster hazard management for seismic settlement zones, to reduce deaths and economic losses.

"More effective prevention strategies would save not only tens of billions of

dollars, but save tens of thousands of lives. Funds currently spent on intervention

and relief could be devoted to enhancing equitable and sustainable development

instead, which would further reduce the risk for war and disaster. Building a

culture of prevention is not easy. While the costs of preventions have to be paid in present, its benefits lie in a distant future. Moreover, the benefits are not tangible:

they are the disasters that did NOT happen" [2].

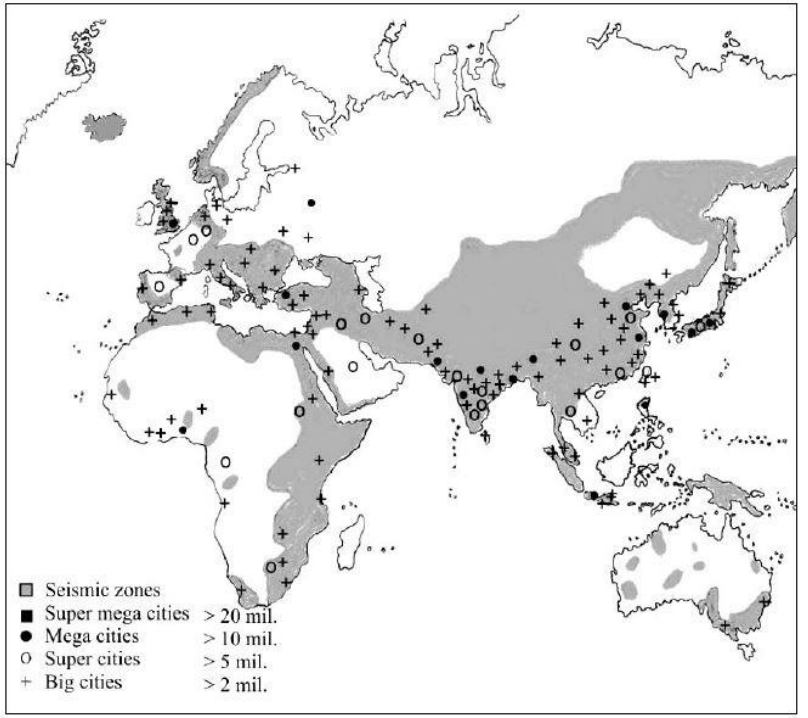

Fig. 3. Gross Domestic Product (GDP) represents the marked value of goods and services

produced by labor and property in a country (BEA, 2005). The GDP per capita is

the ratio:

GDP per capita $=$ GDP/total population

being used as an indicator giving an idea of goods and services available to the

residents of a country, and representing the material well-being of the population (Gioncu,Victor, and Federico,Mazzolani. , CRC Press LLC, 2010 - Earthquake Engineering for Structural Design ProQuest Ebook Central [p.7])

\section{Designing for Earthquakes}

"As time pass by humans began to understand the disaster earthquake better and better. So, we improved the way building has been built and the resistance of them. Mostly old buildings been replaced by new ones, so the city's getting safer. Therefore, the formula of the international building code has changed from $\mathrm{F}=\mathrm{CW}$ to $\mathrm{V}=\mathrm{Cs} \mathrm{W}$. This new formula is much more sophisticated and comes from a long way of analytics and experience. To bring you closer to formula, I explain the meaning of each letter. $\mathrm{V}$ is called the "seismic base shear", it can be explained as what the base of the building needs to resist. W is the "effective seismic weight", which is equal to the to the dead load or weight of the building and also other loads like snow loads and various others. And Cs is called the "seismic response coefficient", which can be read out of formulas and tables depending on the seismic activity at the determent area. Also, while using this formula you have to consider what type of building you are planning. A building of Group IV, which includes hospitals, power stations, emergency shelters, and fire and police stations must resist higher seismic share forces. These buildings are also called "essential facilities". The roman numbers from I to IV are used to explain the importance categories. So, from now we use earthquakes as pretexts for planning decisions for such things as limiting the height of buildings or damming rivers. We have to consider that earthquakes work like a wrecking ball and can destroy a lot on his way. The next big 
earthquake will test our buildings depending on their density. But as this happens we will evolve and try to make our facilities stronger and better [1].

\section{E. How Does Earthquakes Arise}

The terrifying experience is a strong earthquake. In just a few minutes, family members, houses and belongings can be destroyed. The earthquake is the most horrific compared to any other natural event as it undermines the fundamental stability of human existence and the assurance that it is controlled by this stability. If the brutality of nature threatens the stability, terror and anxiety hit an intolerable level. The seismic vibrations within the Earth are as normal as wind and ice are in the atmosphere. All of the world's lifetime is an ongoing sequence of underground movements with more than one billion quakes a year, an average of one every 30 seconds. And the World is like a constantly rotating human body. The motion is generated by the convection currents that develop in the viscous mantel because of the high temperature and pressure gradients that prevail between the crust and the core. These currents of convection lead to Earth masses, circulation: hot molten lava is released and a cold mass of rock is brought down on Earth (Fig. 4).

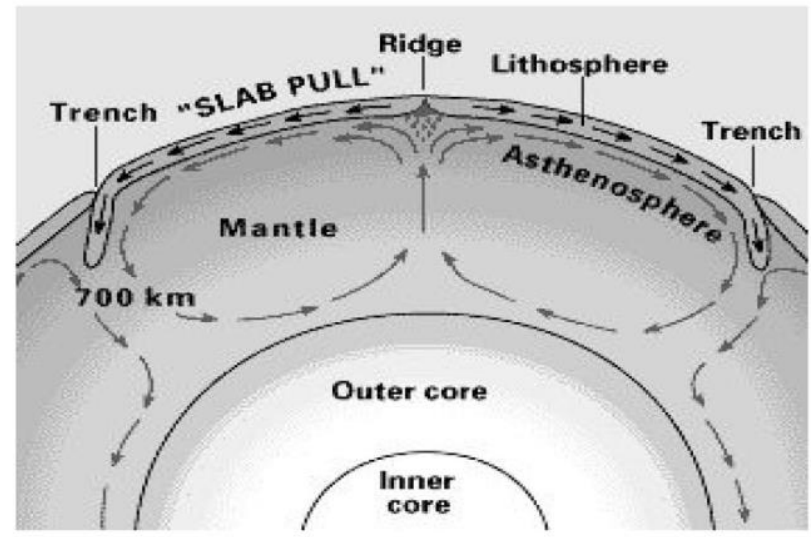

Fig. 4 Convection currents into the Earth (Gioncu,Victor, and Federico,Mazzolani. , CRC Press LLC, 2010 - Earthquake Engineering for Structural Design ProQuest Ebook Central [p.32])

\section{F. Learning from Earthquakes}

"As time pass by humans began to understand the disaster earthquake better and better. So we improved the way building has been built and the resistance of them. Mostly old buildings been replaced by new ones, so the city's getting safer. Therefore, the formula of the international building code has changed from $\mathrm{F}=\mathrm{CW}$ to $\mathrm{V}=\mathrm{Cs} \mathrm{W}$. This new formula is much more sophisticated and comes from a long way of analytics and experience. To bring you closer to formula, I explain the meaning of each letter. $\mathrm{V}$ is called the "seismic base shear", it can be explained as what the base of the building needs to resist. $\mathrm{W}$ is the "effective seismic weight", which is equal to the to the dead load or weight of the building and also other loads like snow loads and various others. And $\mathrm{Cs}$ is called the "seismic response coefficient", which can be read out of formulas and tables depending on the seismic activity at the determent area. Also, while using this formula you have to consider what type of building you are planning. A building of Group IV, which includes hospitals, power stations, emergency shelters, and fire and police stations must resist higher seismic share forces. This buildings are also called "essential facilities". The roman numbers from I to IV are used to explain the importance categories. So from now we use earthquakes as pretexts for planning decisions for such things as limiting the height of buildings or damming rivers. We have to consider that earthquakes work like a wrecking ball and can destroy a lot on his way. The next big earthquake will test our buildings depending on their density. But as this happens we will evolve and try to make our facilities stronger and better.

Despite the considerable effort made over the last few years to resolve the problem of building design in seismic areas satisfactorily, recent earthquakes can cause more damage today than ever before. In the catastrophic decade 1985 to 1995, particularly in the Mexico City, Loma Prieta, Northridge and Kobe earthquakes, there can also be noticed a significant increase in financial losses. A unprecedented rise in the cost of damage in recent years was primarily attributed to urban growth and low seismicity industrialization. The rapid urbanization of metropolitan areas, which was in most cases uncontrolled, helped to make their local authorities and facilities vulnerable. Earthquakes in these regions have been made more recent. As a result of the highly urbanized areas, the events in Izmit and Taiwan have caused great disasters. The incidents show strongly that the development methodologies and requirements of the specification are not unfailing. It is particularly valid when the sources of the earthquake are close to a heavily populated area.

The irony of structural engineers is that while architecture may benefit from collapse but not from performance [3]. [3]. The structural failure leads more to the design of design concepts than to the success of an accident-free building, given that engineers are able to understand what has happened [1]. Partly because the design process is influenced by flaws or faults of human nature, structural defects are triggered. Faults exist because a human spirit in a human context ultimately performs the design process. The development of advanced computational models can not eradicate structural failures. If there are no structural failures, then an over-conservative design can lead to wasted energy that could be best used elsewhere in society [3]. The failure of systems can therefore be viewed as a design advance, rather than a calamity, provided that the lessons of each tragic event are learnt. The main purpose of contemporary earthquakes is therefore only to reduce economic casualties and not to completely eliminate them, thus protecting human life. Disaster training is the key to solving this problem. It is very interesting to note the hastening at the position of some developed trees by 
structural engineers throughout the world in order to examine the damage. Their aims: to understand structural faults better, to assess how structures and installations have collapsed and to discuss them with other places that may be vulnerable to earthquakes." [2]

\section{G. Seismic Risk Mitigation}

"Scientists and engineers do not, however, have the capacity to warn of or forecast an earthquake accurately; they can only try to mitigate their effects. The latest major earthquakes both in the new and old cities revealed the immense social and economic effects of disruptions to structures, work failures and business breaks, underlining the need to implement a consistent seismic engineering approach to build new protect and reinforce existing buildings [1]. For a long time there has been a defaulting attitude among the developers in that they could not bear an earthquake as a deadly force.

Recently a new mindset was established, with the belief that all earthquake-generated processes-even though very complex-are regulated by analyzes, thanks to the important steps forward in seismology and structural engineering. In addition, over the last thirty years, there has been real progress in the understanding of the nature of earthquakes, the impacts of site land and of the structural reactions of seismic structures. The deployment of a large instrument in high-risk earthquake areas gave a lot of knowledge about the main features of ground movement. Simultaneously, the structural analysis of earthquakes is no longer an insoluble problem, due to the development of personal computers and special computer programs. Therefore, today the structural engineers focus on the stage where the actual structural quality can be satisfactorily anticipated, clarified and quantified through strong ground movements.

Recent major earthquakes have however shown that the reality is sometimes distinct from this hopeful view [3]. The lessons learned from these events revealed that there are still many unresolved problems, given the above described significant progress, and it is currently more practical to only think about developments in disaster engineering than about contradictory solutions. In the future, sadly, one can predict the destruction and loss of life from earthquakes. The real misfortune is that this loss of human beings is due to the failure of the constructions and not due to the earthquake itself.

The moral obligation of structural engineers is therefore to minimize the seismic hazard. Such reduction can only be accomplished if the earthquake problems are properly addressed." [2].

\section{H. Survivor of Disaster}

"In the following there is a story about a woman, who survived a tsunami and earthquake which happened 2018 in Palu, Central, 28. September. The deadly wave swept her and thousands of other people in the ocean. She was hit by cars, other peoples bodies, building materials and rocks.
The woman was ready to die on this day. She was floating around for two hours in the ocean until she reached the shore. Her head was bleeding and also she was missing all her clothes. Also she was deaf on one ear. Her story is a miracle. She is speaking of loosing everything on this day and that she wrapped herself up with a banner she found. A 7.4 magnitude earthquake hit central Sulawesi one year ago. The quake was followed by a tsunami and soil liquefaction in several areas. The disaster killed more than 4000 people and hundreds remaining missing. Amid the devastation survivors, life since the disaster has been a never-ending struggle. Many of them have described the slow recovery as a "second disaster". Sri hat to live for 11 months in makeshift tents that she and other victims erected. Recently she was finally able to move into temporary housing, known as Huntara. She and her husband, Martinus, and ther two children, now live in a 12-square-meter room made of plywood. The temporary houses have been mostly built in the four worst-hit-areas- Palu, Sigi, Dongagala and Parigi Moutong, with more than 11.000 units built by the government and private sector. Only a frewhundred permanent homes have been constructed. On one day, hundreds of earthquake survivors, including Sri, held a demonstration in front of the Palu Legislative Council. The survivor complain, that since the disaster they don't get any help from the government not even a grain of rice. Adriansa Manu, the coordinator of Koalisis Sulteng Bergerak (Central Sulawesi) said many victims were still living in tents and around 4.051 people had not received the money they promised to. After demonstrating of three hours some councils got aware of the people and react to it. The government does plan to built houses for the victims, but promised them before to financially support the victims, that they can built their own house. So the victims complain that they can not choose their own which material will be used. Also they want to make clear, that they are not just a project they can make money on [1].

\section{CONCLUSION}

To conclude my investigation about how disasters changed the way we look about built a building in tropical environment I must go through several points. One of the points to look at is the disaster earthquake. We know already that earthquakes happen through moving of the tectonically plates. In the history some of them happened around the world and by starting to analyze them humans start getting better to build more resistible buildings. The damage caused by earthquakes are not only on financial base also a lot of lives been taken by such a disaster. To start from the beginning also the point of urbanization and colonization is one big point to understand the buildings we are looking to today. The numbers say that we will have a constant growth of population and so are the cities and buildings growing. Sure, by time it was possible for humans to use different and new building materials and by getting 
bigger cities and higher buildings we have to consider good constructions. On further analysis it was possible for me to understand that the biggest cities with millions of citizens are mostly located in seismic zones. So, the word tropical environment can be understood in native language, that these are just tropical islands, but it has also have to be registered that these zones are not just reduced to these islands or tropical temperatures. Also, different other countries belong to the tropics. As this said another point, we must look at the gross domestic product, because also this is a very important point. This shows the material wellbeing of one country. When we take Bali as an example, we know that this GDP is not as high like in different other cities. This causes also of having not that proper buildings like in other countries as they don't have enough money for research nor having the best equipment's. But at least engineers and architects all around the world continues to get better by doing research and changed also the formula of an international building code. Buildings are getting better by time and every new disaster will test the durability and maybe a new way will be created. The only things we can do is to reduce the height of buildings and damming rivers for now.

\section{REFERENCES}

[1] William G. Ramroth, 2007 May, Kaplan publishing - Planning for Disaster How natural and manmade disasters shape the built enviromment

[2] Gioncu,Victor, and Federico,Mazzolani. , CRC Press LLC, 2010 Earthquake Engineering for Structural Design ProQuest Ebook Central

[3] Gemma Holliani Cahya and Ruslan Sangadji - Survivor suffer "second disaster" amid slow recovery [p.4] -The Jakarta Post , Saturday 28.09.2019 